\title{
O ENSINO DAS ARTES NA EDUCAÇÃO BÁSICA FRENTE AOS ORDENAMENTOS VIGENTES
}

ARTS EDUCATION IN THE FACE OF CURRENT REGULATIONS

Sonia Regina Albano de Lima ${ }^{1}$ IA- UNESP e FUNADESP soniaalbano@uol.com.br 


\section{Resumo}

O artigo 36 da Lei de Educação Brasileira (LDB no 9.394/96) e seus parágrafos $8^{\circ}, 9 \circ$ e 11 permitem às escolas de ensino médio brasileiras criarem itinerários formativos voltados para o ensino artístico sob diferentes arranjos curriculares. Esses itinerários podem ser realizados na própria instituição ou em parcerias, integrando o ensino técnico e profissional voltado para as artes ao ensino básico, a partir de projetos educacionais ou por meio de convênios com instituições de ensino de artes. Essas iniciativas possibilitam ao estudante do ensino médio cumprir as disciplinas previstas no conteúdo curricular obrigatório e, conjuntamente, realizar uma formação complementar em artes que será integrada ao seu currículo, conforme previsto nos artigos 26 e 35A da LDB no 9.394/96. Este texto é complementar a outros produzidos pela autora aqui enumerados.

Palavras-chave: LDB $n \circ$ 9.394/96; ensino médio; itinerários formativos; parte diversificada do currículo; formação artística.

\section{Abstract}

The section 36 of the Brazilian Education Law (LDB 9394/96) and its 8th, 9th and 11th paragraphs allowed Brazilian high schools to create formative itineraries aiming artistic education under different curricular arrangements. Those initiatives could allow high school students to follow an artistic career, while fulfilling the mandatory elementary curriculum and studying part of it in diversified part of the curriculum a diverse way, as provided in sections 26 and 35A of the Brazilian Education Law (LDB n. 9394/96). This text is a complement to others published by this author.

Keywords: Brazilian education law; high school; formative itineraries; diversified part of the curriculum; artistic education.

\footnotetext{
1 Doutora em Comunicação e Semiótica (ARTES) PUC-SP; Bacharel em Direito ( USP); Bacharel em Instrumento ( FMCG); Licenciatura Curta ( Instituto de São Paulo); Pós-Doutorado pelo GEPI- PUCSP; Professora do Mestrado e Doutorado de Música do IA_UNESP; Coordenadora do Grupo de Pesquisa n. 28 da FUNADESP; Membro do GEPI- PUCSO.
} 


\section{A legislação vigente direcionada ao ensino das artes na educação básica}

A Lei no 13.415, de 16 de fevereiro de 2017, que é uma conversão da Medida Provisória no 746, de 22 de setembro de 2016, foi criada visando alterar e revogar algumas das leis já existentes e instituir a política de fomento à implementação de escolas de ensino médio em tempo integral. No que diz respeito à educação, esta lei alterou alguns dos artigos da LDB no 9.394/96, e a Lei no 11.149, de 20 de junho de 2007, que regulamenta o Fundo de Manutenção e Desenvolvimento da Educação Básica e de Valorização dos profissionais da Educação (Fundeb), também revogou a Lei no 11.161/05, voltada para o ensino da língua espanhola.

No texto que se segue vamos relatar as modificações que esta lei introduziu na LDB no 9.394/96 com relação ao ensino das artes, considerando-se como complementar ao currículo obrigatório a parte diversificada que lhe é complementar, conforme

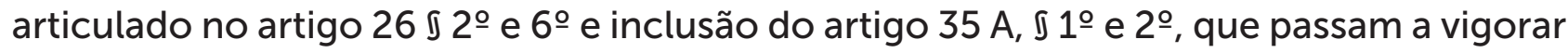
com a seguinte redação:

Art. 26. Os currículos da educação infantil, do ensino fundamental e do ensino médio devem ter base nacional comum, a ser complementada, em cada sistema de ensino e em cada estabelecimento escolar, por uma parte diversificada, exigida pelas características regionais e locais da sociedade, da cultura, da economia e dos educandos.

[1 2ㅇ - O ensino da arte, especialmente em suas expressões regionais, constituirá componente curricular obrigatório da educação básica;

I 60 - As artes visuais, a dança, a música e o teatro são as linguagens que constituirão o componente curricular de que trata o $\mathbb{5} 2^{\circ}$ deste artigo.

Art. 35 A. A Base Nacional Comum Curricular definirá direitos e objetivos de aprendizagem do ensino médio, conforme diretrizes do Conselho Nacional de Educação, nas seguintes áreas do conhecimento:

I - linguagens e suas tecnologias;

II - matemática e suas tecnologias;

III - ciências da natureza e suas tecnologias;

IV - ciências humanas e sociais aplicadas.

T) 1- A parte diversificada dos currículos de que trata o caput do art. 26, definida em cada sistema de ensino, deverá estar harmonizada à Base Nacional Comum Curricular e ser articulada a partir do contexto histórico, econômico, social, ambiental e cultural.

Is 2ㅇ - A Base Nacional Comum Curricular referente ao ensino médio incluirá obrigatoriamente estudos e práticas de educação física, arte, sociologia e filosofia. (BRASIL, 1996, grifos nossos). 
Assim exposto, o texto a seguir pretende discutir como o ensino das artes está sendo ou pode ser realizado nas escolas da educação básica, considerando-se que, mesmo sendo um ensino obrigatório, os artigos citados acima não regulamentam a forma como as Artes são integradas no conteúdo curricular da educação básica via parte diversificada, caso não façam parte do conteúdo curricular obrigatório.

O caput do art. 26 da LDB no 9394/96 prevê, além de uma base comum curricular, uma outra, complementar e diversificada, consideradas as características regionais e locais da sociedade, da cultura, da economia e dos educandos.

A Base Nacional Comum Curricular (BNCC), homologada em 14 de dezembro de 2018 pelo ministro da Educação Rossieli Soares, é um documento de caráter normativo que define o conjunto orgânico e progressivo de aprendizagens essenciais que todos os alunos devem desenvolver ao longo das etapas e modalidades da educação básica, de modo a terem assegurados seus direitos de aprendizagem e desenvolvimento, em conformidade com o que preceitua o Plano Nacional de Educação (PNE). Tem como meta difundir uma educação brasileira que vise à formação humana integral, à construção de uma sociedade justa, democrática e inclusiva (BRASIL, 2018, Apresentação)².

Sua criação objetivou superar a fragmentação das políticas educacionais, promover o fortalecimento do regime de colaboração entre as três esferas de governo e balizar a qualidade da educação. Este documento estabelece dez competências gerais para a educação básica, permeando conhecimentos científicos, artísticos, culturais, e o desenvolvimento pessoal e social. Duas dessas competências reportam-se diretamente à aprendizagem artística:

3. Valorizar e fruir as diversas manifestações artísticas e culturais, das locais às mundiais, e também participar de práticas diversificadas da produção artístico-cultural.

4. Utilizar diferentes linguagens - verbal (oral ou visual-motora, como Libras, e escrita), corporal, visual, sonora e digital -, bem como conhecimentos das linguagens artística, matemática e científica, para se expressar e partilhar informações, experiências, ideias e sentimentos em diferentes contextos e produzir sentidos que levem ao entendimento mútuo. (BRASIL, 2018, p.11).

As Artes, neste ordenamento, estão inseridas na área de conhecimento denominada Linguagens e suas tecnologias, com objetivos, unidades temáticas, habilidades e competências voltadas para as Artes Visuais, a Dança, a Música e o Teatro, corroborando o enunciado do I 6으, art. 26 da LDB nㅇ 9394/96 e reafirmando a polivalência como modalidade pedagógica de ensino artístico. Essas linguagens tanto articulam saberes referentes aos produtos e fenômenos artísticos como envolvem as práticas de criar, ler, produzir, construir, exteriorizar e refletir sobre formas artísticas.

2 Relato do ministro da Educação, Rossieli Soares: "É com alegria que entregamos ao Brasil a versão final homologada da Base Nacional Comum Curricular (BNCC) com a inclusão da etapa do Ensino Médio, e, assim, atingimos o objetivo de uma Base para toda a Educação Básica brasileira. A aprendizagem de qualidade é uma meta que o País deve perseguir incansavelmente, e a BNCC é uma peça central nessa direção, em especial para o Ensino Médio, no qual os índices de aprendizagem, repetência e abandono são bastante preocupantes". Disponível em: http://basenacionalcomum.mec.gov.br/images/BNCC_El_EF_110518_versaofinal_site.pdf. Acesso em: 24 mar. 2020 
No Ensino Fundamental, o componente curricular Arte está centrado nas seguintes linguagens: as Artes visuais, a Dança, a Música e o Teatro. Essas linguagens articulam saberes referentes a produtos e fenômenos artísticos e envolvem as práticas de criar, ler, produzir, construir, exteriorizar e refletir sobre formas artísticas. A sensibilidade, a intuição, o pensamento, as emoções e as subjetividades se manifestam como formas de expressão no processo de aprendizagem em Arte [...]. A aprendizagem de Arte precisa alcançar a experiência e a vivência artística como prática social, permitindo que os alunos sejam protagonistas e criadores. (BRASIL, 2018, p.195).

O documento propõe que a abordagem das linguagens articule seis dimensões do conhecimento artístico que, de forma indissociável e simultânea, caracterizam a singularidade da experiência artística. Tais dimensões perpassam os conhecimentos das Artes Visuais, da Dança, da Música e do Teatro e as aprendizagens dos alunos em cada contexto social e cultural. Não são eixos temáticos ou categorias, mas linhas maleáveis que se interpenetram, constituindo a especificidade da construção do conhecimento em Arte na escola. Não há nenhuma hierarquia entre essas dimensões, tampouco uma ordem para se trabalhar cada uma delas no campo pedagógico. As dimensões veiculadas são: criação, crítica, estesia, expressão, fruição e reflexão (BRASIL, 2018, p.194-195).

\section{A BNCC e a implantação de um ensino artístico interdisciplinar e a parte diversificada do currículo}

Tal relato deixa clara a implantação de um ensino artístico que permeia uma prática pedagógica interdisciplinar, uma vez que vê as artes interligadas aos contextos educativos, socioculturais, políticos, estéticos, filosóficos e econômicos, ampliando as fronteiras entre as linguagens, superando a visão compartimentada e estanque do ensino das artes, reforçando a necessidade de o componente curricular Arte promover um diálogo entre essas linguagens, um diálogo com a literatura e ainda, possibilitar o contato e a reflexão com as formas estéticas híbridas.

Cunha e Lima (2020a, 2020b) discutem e analisam mais intensamente estas questões. Não obstante, Lima (2020) complementa essas discussões ao retratar as diferentes missões pedagógicas do ensino musical brasileiro (LIMA, 2020, p.9-22).

Ainda que a BNCC articule cada linguagem separadamente, a proposta de ensino dessas linguagens não está centrada na aprendizagem técnica e isolada de cada uma das artes, mas na integração destes contextos, estendendo-se ainda para uma quinta unidade temática - as artes integradas. A inserção das Artes integradas reflete a importância que esse documento concedeu à produção artística de estética híbrida, que tem se difundido na contemporaneidade: "[...] uma última unidade temática, Artes integradas, explora as relações e articulações entre as diferentes linguagens e suas práticas, inclusive aquelas possibilitadas pelo uso das novas tecnologias de informação e comunicação" (BRASIL, 2018, p.199). 
Pereira e Souza (2016) relatam que a intenção política de disponibilizar uma base nacional comum capaz de idealizar um currículo nacional que seja comum e homogêneo para todas as escolas da educação básica mais uma vez aponta para o poder centralizador das políticas públicas no tocante às questões curriculares. Entretanto, contar com o termo "parte diversificada", permitindo complementar o currículo obrigatório dessas escolas com questões envolvendo aspectos relevantes da cultura, parece, à primeira vista, uma tendência política de flexibilização da ação hegemônica do Estado. De certa maneira, ela pode se transformar em um dispositivo pedagógico capaz de enriquecer a base comum curricular, permitindo adequar os currículos e práticas educativas à realidade institucional, trazer para a escola temas de relevância social e cultural, contextualizados com a realidade dos alunos e da comunidade escolar como um todo.

J. J Domingues et al. (2000) também acreditam que a parte diversificada do currículo pode atribuir às escolas uma identidade própria e manifestar a vocação de cada uma delas, desde que agregadas à base nacional comum. Segundo estimativa de Ramos e Aquino (2015), 25\% da carga horária dos currículos escolares podem ser veiculados como parte diversificada, fato que propicia aos alunos do ensino médio a possibilidade de intensificar ou dar início ao ensino das Artes para posteriormente ingressar nos cursos superiores destinados ao aprendizado das Artes, seja nas licenciaturas, seja nos bacharelados.

O texto de Pereira e Souza (2016), entre outros objetivos, busca analisar como o termo parte diversificada do currículo se desenvolve e de que maneira os textos políticos se reportam a ele. Os autores consideram que o termo se consolida em uma política que apresenta um espaço narrativo capaz de produzir práticas curriculares com base na cultura local, por meio de ações políticas cotidianas em interlocução com políticas educacionais que são interpretadas e traduzidas no contexto da prática. A parte diversificada do currículo não sintetiza conhecimentos, mas está interligada a uma base nacional comum, estando, portanto, à borda do fazer curricular dos sujeitos da escola (PEREIRA; SOUSA, 2016, p.452-453).

Conforme expresso pelos autores, o termo já havia sido contemplado na Resolução CNE/CEB n우 04/2010, artigo 15, đ 1ㅇ, como complementar à base nacional comum, pois permitia o estudo das características regionais e locais da sociedade, da cultura, da economia e da comunidade escolar, perpassando todos os tempos e espaços curriculares constituintes do ensino fundamental e do ensino médio. $O$ I $1^{\circ}$ desta Resolução revelava que a parte diversificada do currículo comum poderia ser organizada em temas gerais, na forma de eixos temáticos, selecionados colegiadamente pelos sistemas educativos ou pela unidade escolar (BRASIL, 2010).

Para eles, a parte diversificada do currículo deveria ocorrer de forma dialógica, de acordo com a realidade de cada escola, de maneira a atender não só à cultura local, mas às escolhas, às experiências e aos conhecimentos a serem ofertados aos estudantes, ao longo do processo de escolarização. Tal possibilidade traria para as escolas maior autonomia na elaboração de suas propostas curriculares e a liberdade de referendar parte da cultura de uma determinada região. Eles entendem que, se esta parte diversificada não ocupar um espaço significativo nas práticas curriculares das escolas e não tomar a 
cultura local como elemento central, será destituída de valor pedagógico; portanto, é pertinente que as escolas promovam um diálogo mais intenso entre o conhecimento e a cultura e que pensem o currículo como uma produção cultural.

\begin{abstract}
A parte diversificada dos currículos é uma política que se insere na base nacional comum, sendo também normativa e precária no sentido de garantir que as instituições escolares "implementem" suas próprias propostas curriculares tomando a cultura como elemento central. Ao se perceber que a parte diversificada quase não tem espaço nas práticas curriculares, constatamos que a mesma não passa de um discurso redundante e vazio em torno da construção de um currículo nacional e comum. (PEREIRA; SOUSA, 2016, p.456).
\end{abstract}

Esta argumentação é relevante quando direcionada aos estudos e práticas artísticas, principalmente se levarmos em conta que as áreas de conhecimento indicadas nos incisos I a IV do artigo 35 A da LDB n 9.394/96 e a redação do \ 2ㅇ deste artigo deixam mais ou menos evidente que o ensino das Artes integrará a parte diversificada do currículo em um percentual equivalente a $25 \%$, dependendo da região onde isso possa se concretizar e dificilmente será parte do currículo obrigatório dessas escolas. Trata-se de um percentual pequeno, mas que, em razão do ensino artístico na educação básica ser obrigatório, ele poderá se concretizar a partir dessa abertura.

Contudo, é preciso relatar que, se considerarmos que a parte diversificada do currículo é complementar à base comum e que poderá ser organizada em temas ou eixos temáticos, há que se presumir que o ensino artístico não encontrará muito espaço em regiões menos favorecidas do país, pois assuntos e questões mais emergentes serão priorizados. Mesmo sendo obrigatório nas escolas de educação básica, seja como disciplina, seja como atividade artística, a política educacional do país ainda privilegia bem mais intensamente a formação de um indivíduo para o mundo do trabalho, dirimindo a importância de uma formação artística desses alunos.

Também deve se considerar o contingente mínimo de professores de Arte que atuam no país. Muitas regiões contam com professores de Arte na educação básica formados em outras áreas e que, por conta da obrigatoriedade deste ensino, dão aulas de Arte apenas para cumprir as determinações legais destinadas à educação básica. Diante desses argumentos, presume-se que o ensino das Artes ocupará um lugar de pouca projeção no currículo escolar no ensino fundamental e menos ainda no ensino médio, mesmo que integrado à parte diversificada do currículo.

Embora o I 70 do artigo 35A da LDB n 9.394/96 tenha determinado que os currículos do ensino médio devem considerar a formação integral do aluno, de maneira a adotar um trabalho voltado para a construção de seu projeto de vida e para sua formação nos aspectos físicos, cognitivos e socioemocionais, fica evidente que a formação artística, mesmo que obrigatória, não ocupará o patamar alcançado pelas demais linguagens se não houver um empenho institucional, seja da parte dos gestores, dos coordenadores de cursos ou do corpo docente. Ele também poderá não integrar a parte diversificada do currículo e disseminado em práticas artísticas esporádicas e nas festas comemorativas em razão de temáticas mais relevantes a determinadas regiões do país. 


\section{Os equívocos do ensino polivalente das Artes na educação básica em contraposição a uma formação docente unicista}

A afirmativa acima exposta se consolida na leitura do inciso II do artigo 35 da LDB destinado ao ensino médio, que traz como finalidade a preparação básica para o trabalho e a cidadania do educando, de modo a ser capaz de se adaptar com flexibilidade às novas condições de ocupação ou aperfeiçoamento posteriores (BRASIL, 1996). Por sua vez, o artigo 22 e o $02^{\circ}$ do artigo $1^{\circ}$ da LDB n 9.394/96 reafirmam essa tendência: "A educação escolar deverá vincular-se ao mundo do trabalho e à prática social" (BRASIL, 1996).

É clara a preocupação do legislador em privilegiar uma formação curricular bem mais voltada para o mundo do trabalho do que para o ensino das Artes, considerando-se que esta formação artística é desejada por uma parcela mínima da sociedade, ainda que a Arte, de modo geral, auxilie em grande parte o desenvolvimento integral dos indivíduos e seja uma parte importante da cultura de um país.

A própria BNCC, ao se reportar ao ensino das artes no ensino fundamental, deixa clara a difusão de uma proposta pedagógica que privilegia mais atentamente as práticas artísticas, e não tanto o aprendizado das quatro linguagens.

Ao longo do ensino fundamental, os alunos devem expandir seu repertório e
ampliar sua autonomia nas práticas artísticas, por meio da reflexão sensível,
imaginativa e crítica sobre os conteúdos artísticos e seus elementos constituti-
vos e também sobre as experiências de pesquisa, invenção e criação. Para tanto,
é preciso reconhecer a diversidade de saberes, experiências e práticas artísticas
como modos legítimos de pensar, de experienciar e de fruir a Arte, o que coloca
em evidência o caráter social e político dessas práticas. (BRASIL, 2018, p.196,
grifos nossos).

Em outro momento, a BNCC relata que as habilidades artísticas serão organizadas com o intuito de permitir que os sistemas e as redes de ensino, as escolas e os professores organizem seus currículos e suas propostas pedagógicas nesta área com a devida adequação aos seus contextos, sem pensar numa programação sequencial e linear desta programação curricular: "A progressão das aprendizagens não está proposta de forma linear, rígida ou cumulativa com relação a cada linguagem ou objeto de conhecimento, mas propõe um movimento no qual cada nova experiência se relaciona com as anteriores e as posteriores na aprendizagem de Arte" (BRASIL, 2018, p.197).

Um tanto equivocada essa normatização, porque, ao mesmo tempo que propaga um ensinamento polivalente das linguagens artísticas de forma não linear e rígida, propõe que as experiências artísticas sigam uma inter-relação temporal, umas com as outras, pressupondo um ensino contínuo dessas práticas, o que se configura bastante ilusório em nosso país, considerando-se a impossibilidade de um ensino artístico seguir da educação infantil para os anos iniciais e finais do ensino fundamental, com continuidade para o ensino médio. 
Também as competências artísticas especificadas neste documento destinadas ao ensino fundamental me parecem um tanto complexas para serem repassadas aos alunos, ainda mais se considerarmos que estas instituições escolares não seguem uma programação artística curricular seriada; via de regra, não possuem um planejamento curricular adequado e contemplam uma carga horária mínima para o repasse desses conhecimentos. Em grande parte dessas escolas, esse conhecimento é transmitido via atividades artísticas esporádicas, sem grandes preocupações cognitivas. Inúmeros artigos publicados apontam para essas incongruências.

Para exemplificar a complexidade das propostas apresentadas por esse ordenamento, vejamos o que diz o item II da BNCC com respeito ao ensino das Artes nos anos iniciais do ensino fundamental: "Compreender as relações entre as linguagens da Arte e suas práticas integradas, inclusive aquelas possibilitadas pelo uso das novas tecnologias de informação e comunicação, pelo cinema e pelo audiovisual, nas condições particulares de produção, na prática de cada linguagem e nas suas articulações" (BRASIL, 2018, p.197).

A leitura dos demais itens demonstra o quanto os ordenamentos voltados para a educação artística se encontram distanciados de uma realidade sociocultural, que, em grande parte, traz para a educação básica um aluno com um conhecimento cultural bem diferente daquele idealizado por esses legisladores.

Outra questão a ser considerada reporta-se ao ensino artístico centrado na polivalência, termo advindo da Lei no 5.692/71, que priorizou, entre outras medidas, o ensino das diversas linguagens artísticas (artes visuais, dança, teatro e música) nas escolas de educação básica. A partir dessa orientação, no passado foram criadas as licenciaturas em Educação Artística, que objetivavam repassar para o docente o conhecimento de todas as linguagens artísticas em um só curso. Se a princípio essa formação pareceu adequada, no decorrer dos anos ela se manifestou insuficiente, pois os docentes advindos desses cursos não conseguiam repassar aos seus alunos os conhecimentos básicos de cada uma dessas linguagens em condições igualitárias, predominando o ensino das artes visuais. Ficou provado ao longo dos anos que essas licenciaturas habilitavam docentes não capacitados para ensinar todas as linguagens artísticas exigidas pelos ordenamentos e que o conhecimento artístico obtido nesses cursos beirava a superficialidade.

Nesse sentido, as licenciaturas em Educação Artística foram substituídas pelas licenciaturas em Arte, capazes de habilitar o docente em uma das quatro linguagens indicadas na LDB no 9.394/96. Entretanto, ao adentrar em sala de aula, este professor, habilitado em uma única linguagem artística, teria de repassar aos seus alunos os conhecimentos referentes às quatro linguagens, conhecimentos esses que não lhe foram ofertados em sua formação.

Se as licenciaturas em Arte possibilitaram uma compreensão mais sólida de uma determinada linguagem artística, não adequaram este professor para uma atuação pedagógica polivalente, o que faz concluir a incongruência existente entre a formação docente adquirida e a sua atuação em sala de aula - uma formação tecnicista incompatível com uma atuação polivalente e interdisciplinar que prioriza outra forma de ensinar Arte. 
Outro problema, como exposto mais acima, está focado na descontinuidade do ensino artístico nos diversos níveis da educação básica e na falta de professores de Arte habilitados em cursos superiores para atuar na educação básica. Em alguns estados e cidades brasileiras, muitas vezes este ensino é realizado por professores de outras áreas de conhecimento, devido à falta de um profissional habilitado para essa função. Tal problemática exige a reformulação curricular das licenciaturas, que deverão capacitar docentes para o ensino das Artes na educação básica sob uma perspectiva polivalente e interdisciplinar, como rezam os ordenamentos da área, relativizando-se o sentido pejorativo atribuído ao termo polivalência e conferindo-lhe um sentido mais interdisciplinar, como o enunciado nos artigos de Cunha e Lima (2020), bem como instituindo uma formação artística para esses alunos, que se estenda a todos os níveis dos ensinos fundamental e médio, de forma continuada.

Medidas dessa natureza trarão ao ensino artístico maior importância, já que a Arte foi reconhecida pela LDB no 9.394/96 como uma das áreas de conhecimento, portanto, de alguma forma ela deve incorporar a matriz curricular dos cursos de educação básica, seja no currículo obrigatório ou sob condições implantadas na parte diversificada do currículo.

\section{Possíveis soluções legais para a propagação do ensino artístico na educação básica}

Uma solução possível para inserir as Artes nessas escolas encontra-se no artigo 36 da LDB no 9.394/96, onde os itinerários formativos do ensino artístico poderão ser organizados por meio da oferta de diferentes arranjos curriculares, conforme a relevância local e a possibilidade dos sistemas de ensino.

O If $8^{\circ}$ do artigo 36 deste ordenamento permite ao aluno que o aluno obtenha, na própria instituição ou em parceira com outras instituições, a formação técnica e profissional a que se reporta o inciso $V$ deste artigo, desde que tal oferta seja aprovada previamente pelo Conselho Estadual de Educação e homologada pelo secretário estadual de Educação e certificada pelos sistemas de ensino. O I $9{ }^{\circ}$ desse dispositivo legal prevê que essas instituições de ensino emitam certificados com validade nacional, habilitando, dessa forma, o concluinte do ensino médio a prosseguir seus estudos em nível superior ou em outros cursos ou formações para os quais a conclusão do ensino médio seja etapa obrigatória.

Para o cumprimento das exigências curriculares implantadas para o ensino médio, o I 11 deste dispositivo legal também prevê que os sistemas de ensino poderão reconhecer competências e firmar convênios com instituições de educação a distância com notório reconhecimento, mediante as seguintes formas de comprovação: I - demonstração prática; II - experiência de trabalho supervisionado ou outra experiência adquirida fora do ambiente escolar; III - atividades de educação técnica oferecidas em outras instituições de ensino credenciadas; IV - cursos oferecidos por centros ou programas ocupacionais; $V$ - estudos realizados em instituições de ensino nacionais ou estrangei- 
ras; VI - cursos realizados por meio de educação a distância ou educação presencial mediada por tecnologias. Neste último item, observa-se a importância que os ordenamentos têm conferido aos processos de ensino a distância e de que forma a tecnologia cada vez mais está presente na educação brasileira.

Uma possibilidade permitida pela própria lei parece ser capaz de contribuir para que o ensino artístico seja integrado à educação básica com certa eficiência, a saber: 1) a criação de projetos educativos comprometidos com essa modalidade de ensino que correrão à parte da carga curricular obrigatória e que poderão se constituir em uma parte diversificada; e 2) a criação de convênios com instituições de ensino técnico e instituições de ensino artístico não formal que desenvolvam estudos específicos em cada uma dessas linguagens.

Essas duas medidas não só poderão ser introduzidas nas escolas de educação básica; de forma indireta, poderão aumentar a procura e o ingresso desses alunos nos cursos de Licenciatura em Artes, que receberão alunos mais bem preparados. Possibilitarão, ainda, ao estudante do ensino médio que pretenda seguir uma carreira artística, uma formação mais sólida, e permitirão, aos estudantes da educação básica, iniciar uma formação que se estenderá por toda sua vida, se assim ele quiser. Tais medidas trariam para os cursos de Licenciatura em Artes um aluno capaz de desenvolver sua formação de maneira mais adequada e ampliariam as possibilidades de um aprendizado artístico que contribuiria mais acertadamente no desenvolvimento integral dos indivíduos, atendendo ao que dispõem os ordenamentos acima referendados.

Obviamente esta tarefa ficaria a cargo das instituições e docentes da educação básica e dos cursos superiores, no sentido de promover este intercâmbio. Muitas universidades públicas têm incorporado, em seus cursos superiores, escolas de ensino de Artes, visando introduzir em seu corpo discente um aluno mais habilitado para exercer essa profissão. Essas medidas poderiam ser realizadas na própria instituição ou em parcerias firmadas com escolas técnicas de ensino de Arte.

É importante mencionar que as alterações dos artigos da LDB n 9.394/96 acima relatadas trazem a possibilidade de o ensino artístico estar integrado à educação básica via parte diversificada do currículo, correndo em paralelo ao conteúdo curricular obrigatório, seja na instituição ou fora dela. Atividades e vivências artísticas nas escolas de ensino fundamental e médio ou mesmo o ensino das Artes realizado em centros específicos ao aprendizado das linguagens artísticas trariam um diferencial considerável ao ensino artístico, uma vez que na educação básica ele é bem distinto daquele realizado em espaços e instituições diretamente focados na capacitação de jovens para este aprendizado.

Inúmeras publicações têm criticado o modo como se processa o ensino das Artes nas escolas de educação básica, seja pela escassez de horário destinada a esta disciplina, seja pela descontinuidade de conteúdos e propostas de ações docentes veiculadas desde o ensino infantil até o ensino médio, ou pela falta de uma formação básica para que esse conhecimento se prolifere como indispensável ao desenvolvimento humano, não só sob um viés cognitivo, mas também psicológico, físico e estético.

Na cidade de São Paulo, no que diz respeito ao ensino musical, parcerias signifi- 
cativas poderiam ser realizadas com escolas de ensino não formal de música ligadas à Prefeitura e ao Estado, entre elas, a Escola Municipal de Música de São Paulo (EMMSP), a Escola Municipal de Iniciação Artística (Emia), a Escola de Música do Estado de São Paulo (Emesp), sem esquecer a Escola Técnica Estadual de Artes (Etec). Parte do ensino integral destinado à educação básica poderia ser realizada nesses centros de estudo, que oferecem condições infraestruturais e assistência pedagógica bem mais específicas e direcionadas para esse aprendizado.

Essa atitude não descarta a hipótese de que esse mesmo trabalho possa ser realizado na própria instituição de ensino, através de projetos interdisciplinares voltados para esse aprendizado. O trabalho interdisciplinar realizado pela educadora Caroline Cao Ponso (2008), em torno de experiências realizadas com a música em uma escola de educação infantil, na cidade de Porto Alegre, com alunos cuja faixa etária varia de um ano e meio a seis anos, é um exemplo dessa atuação docente. Nessa ação foram realizadas pontes e redes interdisciplinares com outras áreas de conhecimento. As ações docentes foram conduzidas por projetos pedagógicos delineados pela escola e pelos docentes, interligando a música com a literatura infantil, com o desenho, com a matemática e com a mídia. Conforme expressa Ponso: “[...] como professora de música, procurei demonstrar as pontes que surgiram entre as aulas de música e os projetos de investigação que ocorreram dentro de um ano de trabalho. Busquei evidenciar a inter-relação entre a música e as temáticas abordadas e de que forma elas se ampararam" (2008, p.76).

Outra medida benéfica seria a implantação de licenciaturas interdisciplinares de Arte, que adotariam outras possibilidades de formação de professores de Arte mais coerentes com a perspectiva pedagógica polivalente e interdisciplinar proposta pela BNCC e demais ordenamentos da área. Algumas delas já estão funcionando em alguns estados brasileiros e parecem cumprir bem esse objetivo.

Esses cursos buscam integrar todas as linguagens artísticas em um só contexto, sem dar ênfase a nenhuma delas, e oferecem uma formação artístico-pedagógica focada na educação básica. Seus professores comportam diferentes habilitações nas diversas linguagens artísticas e oferecem um conhecimento artístico sequencialmente organizado, coerente, articulando vivência, expressão e compreensão dos saberes das manifestações artísticas, na convergência de linguagens em processos criativos e poéticas da arte contemporânea. Eles ainda oferecem uma formação docente qualificada de acordo com a realidade escolar e o conhecimento dos fundamentos de metodologias das diferentes linguagens artísticas. Eles se propõem a formar um docente de arte capaz de ensinar e transitar pelas diferentes linguagens artísticas, confluindo-as e integrando-as. Estas graduações não oferecem habilitação específica nem complementar com ênfase em uma das linguagens artísticas, pelo contrário, elas oferecem uma formação interdisciplinar com abordagem equânime entre as linguagens artísticas, proporcionando uma formação docente mais ampla, abrangendo tanto os conteúdos das artes visuais, da dança, do teatro, como o da música.

Não é possível afirmar que essas propostas e a missão pedagógica dessas licenciaturas poderão, em um futuro próximo, se diferenciar das projetadas no passado, nos 
cursos de Educação Artística. O tempo poderá comprovar a eficácia desses cursos, o fato é que já estão surgindo concursos públicos em regiões que têm abrigado alguns docentes portadores dessas licenciaturas.

Os alunos dos estágios supervisionados obrigatórios nos cursos de Licenciatura em Artes também poderiam ser de grande valia para as escolas de educação básica. A Coordenação Pedagógica, em parceria com esses estagiários, poderia criar projetos interessantes para que esse ensino se propagasse, principalmente em centros ou regiões em que há escasso número de professores de Arte, auxiliando esses futuros docentes a reconhecer os desafios que sua carreira oferecerá, no sentido de agregar trabalho e escola, teoria e prática.

\section{Considerações finais}

Entendo que todas as possibilidades de ensino artístico aqui propagadas devem ser mantidas, pois percorrem destinos, missões e funções pedagógicas diferenciadas. A educação básica, a educação superior, o ensino profissionalizante em Artes e até mesmo o ensino artístico não formal devem ser preservados, já que cada uma dessas formações tem objetivos e missões pedagógicas relevantes para a área. Contudo, os dispositivos legais voltados para a educação básica necessitam ser atendidos; nesse sentido, a parte diversificada do currículo e as propostas acima veiculadas podem trazer para este ensino uma abertura mais adequada e eficaz.

A temática aqui relatada é bastante complexa e não poderia ser narrada em um único artigo. Muitos artigos já publicados por mim estão centrados na discussão desses questionamentos. Neste artigo foram referendados mais enfaticamente os textos legais voltados para o ensino das Artes na educação básica, bem como algumas das vivências que obtive no gerenciamento e no exercício da docência em uma escola de música direcionada para o ensino técnico de música em uma instituição de ensino superior por cerca de mais de três décadas. Trata-se, portanto, de um texto não voltado para discussões iminentemente teóricas, mas um artigo que busca tratar desta temática sob um viés prático e vivenciado.

\section{Referências}

BRASIL. Lei de Diretrizes e Bases da Educação Nacional. Lei n. 9.394/96, de 20 de dezembro de 1996. Estabelece as diretrizes e bases da educação nacional. Diário Oficial da União, Brasília, DF, 1996. Disponível em: https://www.planalto.gov.br/ ccivil_03/Leis/L9394.htm. Acesso em: 10 mar. 2020.

BRASIL. Ministério da Educação. Base Nacional Comum Curricular. Define o conjunto 
orgânico e progressivo de aprendizagens essenciais que todos os alunos devem desenvolver ao longo das etapas e modalidades da Educação Básica. 3. rev. Brasília: MEC, 2018. Disponível em: http://basenacionalcomum.mec.gov.br/images/BNCC_EI_ EF_110518_versaofinal_site.pdf. Acesso em: 10 mar. 2020.

BRASIL. Ministério da Educação. Resolução n. 4, de 13 de julho de 2010. Define Diretrizes Curriculares Nacionais Gerais para a Educação Básica. Brasília: MEC/CNE/ CEB, 2010.

CUNHA, Daiane Solange Stoeberl da; LIMA, Sonia R. Albano de. O ensino de arte para a educação básica à luz dos ordenamentos vigentes: paradoxos em análise. Revista da Tulha, v. 6, n. 1, p. 78- 109, 2020a.

CUNHA, Daiane Stoeberl da; LIMA, Sonia R. Albano de. A interligação da polivalência com a interdisciplinaridade e o ensino integrado das artes. Revista Música, v. 20, n. 1, p. 97-120, jul. 2020b. DOI: 10.11606/RM.V20I1.169940

DOMINGUES, J. L.; TOSHI, N. S.; OLIVEIRA, J. F. A reforma do ensino médio: uma nova formulação curricular e a realidade da escola pública. Revista Educação e Sociedade, ano XXI, n. 70, p. 63-77, abr. 2000. Disponível em: https://www.scielo.br/pdf/es/ v21n70/a05v2170.pdf. Acesso em: 20 mar. 2020.

LIMA, Sonia Regina Albano de. Ensino musical brasileiro: diferentes missões pedagógicas. In: LIMA, Sonia R. Albano de (org.). Ensino musical brasileiro: múltiplos olhares. São Paulo: Musa, 2020. p. 9-22.

PEREIRA, Maria Zuleide da Costa; SOUSA, Jorge Luis Umbelino de. Parte diversificada dos currículos da educação básica: que política é essa? Espaço do currículo, Paraíba, v. 9, n. 3, p. 448-458, set./dez. 2016.

PONSO, Carolino Cato. Música em diálogo: ações interdisciplinares na educação infantil. Porto Alegre: Sulina, 2008.

RAMOS, P. S.; AQUINO, K. A. S. Ações na parte diversificada do currículo: um relato de experiência na perspectiva de uma aprendizagem significativa crítica. Cadernos de Estudos e Pesquisa na Educação Básica, Recife, v. 1, n. 1, p. 240-249, 2015. Disponível em: https://periodicos.ufpe.br/revistas/cadernoscap/article/viewFile/15005/17840. Acesso em: 23 mar. 2020. 
Sonia Regina Albano de Lima é doutora em Comunicação e Semiótica - Artes (PUC-SP), pós-doutora em Interdisciplinaridade e Educação pelo Gepi/PUC-SP; pós-doutora em Música pelo IA/Unesp; bacharela em Instrumento - Piano (FMCG); bacharela em Direito (USP). Desde 2005 atua no Programa de Mestrado e Doutorado em Música do IA/Unesp. Possui livros, coletâneas, artigos e pesquisas envolvendo interdisciplinaridade, música, performance e educação musical. Foi Presidente da Anppom no período de 2015 a 2019. 